\title{
TRABALHO EM EQUIPE E REUNIÕES MULTIPROFISSIONAIS DE SAÚDE: UMA CONSTRUÇÃO À ESPERA PELOS SUJEITOS DA MUDANÇA
}

\author{
MULTIDISCIPLINARY MEETINGS:THE HEALTH TEAM WORK IN CONSTRUCTION AND WAITING \\ FOR THE SUBJECTS OF CHANGE
}

\author{
Cíntia Garcia Cardoso ${ }^{1}$ \\ Élida Azevedo Hennington ${ }^{2}$
}

Resumo Este artigo apresenta resultados parciais de pesquisa que visou a apreender como os trabalhadores vivenciam as relações interprofissionais no contexto das práticas de atenção à saúde em doenças infecciosas em setor de internação hospitalar de instituto de pesquisa. Enfoca o trabalho em equipe a partir da rotina dos profissionais que lá atuam e das reuniões multiprofissionais em saúde. O referencial teórico-metodológico articulou contribuições da ergologia de Schwartz com reflexões da Política Nacional de Humanização. A pesquisa qualitativa utilizou técnicas de observação participante e entrevistas semiestruturadas para a produção de dados. A análise do material empírico foi realizada com base no referencial da análise de conteúdo em sua vertente temática. Dentre os principais resultados, observou-se que os trabalhadores desejam encontrar uma forma efetiva de trabalhar em equipe que resulte numa atenção à saúde integral e humanizada, porém prevalece uma postura de espera pelo sujeito das mudanças. Isto demonstra a necessidade de se fomentar o protagonismo desses sujeitos, tornando visível a gestão que os trabalhadores da saúde fazem do seu próprio processo de trabalho, bem como aprimorar mecanismos de gestão participativa com a ampliação do grau de transversalização entre os sujeitos envolvidos no cuidado, numa perspectiva de gestão em que todos sejam corresponsáveis pelos rumos da atenção prestada.

Palavras-chave trabalho em equipe multiprofissional; relações interprofissionais; humanização da assistência hospitalar; doenças infecciosas; ergologia.
Abstract The article focuses on team work within multiprofessional health meetings. It presents results of a research that intended to understand how workers experience the inter-relationships, in the context of health care practices in infectious diseases in the hospitalization sector of a Research Institute. The theoretical and methodological references articulated contributions of Schwartz's Ergology and the National Policy of Humanization. The qualitative research used observation techniques and semi-structured interviews. The analysis of empirical material was based on the technique of content analysis in its thematic analysis. Among the main results, we found that workers want to find an effective way to work in teams, resulting in a comprehensive and humanizing health care, but a prevailing attitude of waiting for the subject of change, demonstrates the need to make the management they do of their own work process become visible, to encourage the protagonism of subjects and a management perspective in which all subjects can feel co-responsible for the direction of health care provided.

Keywords multiprofessional team work; interprofessional relations; humanization of hospital care; infectious diseases; ergology. 
Considera-se que o trabalho em equipe multiprofissional representa um dos pontos centrais na reorganização da atenção à saúde no Sistema Único de Saúde (SUS), sustentada por projetos assistenciais mais integrais e resolutivos que promovam mudanças nos processos de trabalho e nas formas de atuar sobre o processo saúde-doença através de uma maior interação entre os profissionais e suas ações (Costa, Enders e Menezes, 2008). O trabalho em equipe surge como uma estratégia para redesenhar os processos de trabalho e promover a qualidade dos serviços. Embora haja muitos modelos conceituais demonstrando a sua importância, existe ainda também muita indefinição em torno dos conhecimentos, habilidades e atitudes necessárias para concretizá-lo no cotidiano dos serviços (Pinho, 2006).

A importância da equipe multiprofissional na saúde é referida por diversos autores e justificada de várias formas. Colomé, Lima e Davis (2008) afirmam ser preciso desenvolver um trabalho conjunto no qual todos os profissionais se envolvam em algum momento na assistência, de acordo com seu nível de competência específico, e possam conformar um saber capaz de dar conta da complexidade dos problemas de saúde.

Para Schraiber e colaboradores (1999), diante das múltiplas dimensões que as necessidades de saúde expressam - social, psicológica, biológica e cultural - e do intenso processo de especialização do conhecimento e das intervenções acerca desse objeto complexo, nenhum agente isolado tem a capacidade de realizar a totalidade das ações demandadas e necessárias. A equipe representa, além de relações de trabalho, relações de saberes, poderes e, principalmente, relações interpessoais. Esse modo de trabalhar exige que os profissionais utilizem seus saberes operantes particulares, baseados em distintas lógicas de julgamento e de tomada de decisão quanto à assistência a se prestar, de forma compartilhada e negociada. Tal articulação implica a conexão de diferentes processos de trabalho, conhecimento sobre o trabalho alheio e o reconhecimento pelo outro de sua necessidade para a atenção à saúde (Colomé, Lima e Davis, 2008; Fortuna et al., 2005; Lima e Almeida, 1999; Schraiber et al., 1999).

Peduzzi (2007) aponta nessa mesma direção, ao justificar que intervir na realidade do trabalho em equipe significa promover a mudança das práticas de saúde, no sentido da integração das ações e dos trabalhadores, buscando assegurar assistência e cuidado que respondam de modo pertinente no sentido ético, técnico e comunicacional às necessidades de saúde dos usuários e da população de referência dos serviços. Para esta autora, o trabalho em equipe multiprofissional pode ser definido como a modalidade de trabalho coletivo que se configura na relação recíproca entre as múltiplas intervenções técnicas e a interação dos agentes de diferentes áreas profissionais, em que a articulação das ações e a cooperação ocorrem através da comunicação. Por meio da relação dialética, entre trabalho e interação, 
os agentes podem construir um projeto assistencial comum e pertinente para a atenção integral às necessidades de saúde dos usuários, configurando, então, duas dimensões: a articulação das ações e a interação dos agentes (Peduzzi, 1998, 2001; Silva e Trad, 2004/2005).

A concepção de equipe como um grupo de pessoas que realiza algo em conjunto é trazida por Gomes, Anselmo e Lunardi Filho (2000), que referem como característica essencial do trabalho em equipe a liberdade conferida a todos os membros de contribuir com ideias e opiniões para solucionar problemas. Este tipo de trabalho pressupõe a possibilidade da prática de um profissional se reconstruir na do outro. Assim, ambos se transformam nessa troca no intuito de intervir na realidade que se apresenta e se revela complexa, por reunir indivíduos com diferentes histórias de vida, saberes técnicos e formações diversas, em torno da difícil tarefa de responder adequadamente às necessidades dos usuários do serviço, da própria instituição, bem como aos desejos e à individualidade de cada membro da equipe (Araújo e Rocha, 2007; Canoletti, 2008).

A simples composição de equipes nos serviços não corresponde necessariamente à configuração de um 'trabalho em equipe'. Percebe-se ainda que, em face das distintas demandas por cuidado de saúde e situações que se apresentam no cotidiano, diversas modalidades de intervenção multiprofissional podem ocorrer (Lima e Almeida, 1999; Schraiber et al., 1999). Aspectos que dizem respeito ao campo das relações interprofissionais - como a autonomia técnica, a complementaridade e interdependência das atividades, a articulação das ações, a forma de comunicação, a construção de consensos, a elaboração de projetos assistenciais comuns, a forma como são tomadas as decisões, entre outros - irão permitir que diversos arranjos se conformem nos serviços: uns levando as relações para uma direção oposta à tentativa de trabalho em equipe; outros contribuindo ou indicando um caminho para sua realização efetiva.

Dentre os principais cenários do trabalho em equipe estão as reuniões multiprofissionais nos serviços, foco deste artigo. Segundo Abuhab e colaboradores (2005), reuniões técnicas fazem parte do processo de trabalho em saúde e permitem a troca de informações e vivências do dia a dia, propiciando um processo participativo e de compartilhamento de saberes. A forma de organizar e a dinâmica da reunião permitem entender se o serviço tende a ser transformador e prioriza a troca e a decisão da equipe em relação às intervenções, ou se é tradicional e submetido ao modelo médico hegemônico.

Este artigo apresenta parte dos resultados de pesquisa que teve como objetivo geral analisar o trabalho em equipe multiprofissional, no contexto das práticas de atenção à saúde em doenças infecciosas do Instituto de Pesquisa Clínica Evandro Chagas, da Fundação Oswaldo Cruz, Rio de Janeiro (Ipec/Fiocruz). O texto enfoca o trabalho em equipe a partir da rotina dos 
serviços e das reuniões multiprofissionais em saúde no setor de internação do instituto. O Ipec, uma das unidades técnico-científicas da Fiocruz, desenvolve atividades de ensino, pesquisa, assistência e desenvolvimento tecnológico e é considerada referência regional e nacional na atenção e pesquisa clínica em doenças infecciosas.

\section{A hegemonia da racionalidade biomédica como norteadora do trabalho em equipe de saúde}

Dentre as diversas denominações encontradas na literatura para o modelo assistencial hegemônico nas práticas de saúde, optamos por utilizar o termo 'modelo biomédico', e a expressão 'racionalidade biomédica' será usada quando tratarmos da lógica que guia a organização dos processos de trabalho e as relações nos serviços onde predomina tal modelo (Barros, 2002; Caprara e Franco, 1999; Koifman, 2001; Peduzzi, 2007).

No modelo biomédico o corpo humano é representado como uma máquina complexa, cujas partes se inter-relacionam e precisam de constante monitoramento, a fim de se detectar doenças que resultam de processos degenerativos internos, de agentes químicos, físicos ou biológicos que o invadem ou da falha de algum mecanismo regulatório do organismo (Koifman, 2001). Este modelo interpreta a doença como um desvio de variáveis biológicas em relação à norma, baseado numa perspectiva mecanicista. Trata fenômenos complexos a partir de princípios simples, como relação de causa e efeito, e considera uma distinção cartesiana entre mente e corpo, abordando-o de forma fragmentada, minimizando aspectos sociais, culturais, psicológicos e comportamentais (Caprara e Franco, 1999).

Entretanto, apesar do avanço tecnológico e científico, assim como da sofisticação da biomedicina, começa a ficar clara a sua impossibilidade de oferecer respostas conclusivas ou satisfatórias para muitos problemas, principalmente para os componentes sociais, culturais e/ou subjetivos que acompanham, em maior ou menor grau, qualquer processo de adoecimento (Barros, 2002).

O modo de organização das instituições de saúde e a própria literatura sobre trabalho em equipe evidenciam que o modelo predominante de organização das práticas é o 'modelo clínico da assistência médica individual' ou 'modelo médico', centrado no saber biomédico e no diagnóstico e tratamento das doenças e sintomas orgânicos. As demais áreas agregam seus trabalhos em torno dessa 'racionalidade' e são comandados por ela, de forma periférica ao trabalho médico, considerado nuclear (Lima e Almeida, 1999; Peduzzi, 1998).

Peduzzi (2007) alerta que nesse modelo muitas vezes ocorre uma "complementaridade periférica instrumental", em que um trabalhador passa a 
ser objeto da ação instrumental do outro, perdendo a perspectiva de sujeito, sendo tratado como um recurso do trabalho alheio. No entanto, o trabalho em equipe exige o entendimento das atribuições e práticas dos demais profissionais e o reconhecimento de que o conhecimento do outro é útil e indispensável. Ou seja, pauta-se em relações de legitimação do outro, pois, ao aceitar o outro como legítimo, percebem-se suas qualidades, potência e desejos, assim como seus defeitos e limites.

Assim, observa-se que a lógica da fragmentação do corpo humano imposta pela biomedicina tem redundado na fragmentação também dos modos de atenção. Gomes, Pinheiro e Guizardi (2005) destacam que estudar a fragmentação, tanto no corpo humano dividido em órgãos e tecidos, quanto entre os profissionais e suas práticas, é relevante por ela estar presente também na relação de objetivação do usuário e/ou ainda na organização dos serviços e do atendimento.

Em contraposição a essa perspectiva fragmentadora e mecanicista, o SUS preconiza a atenção integral em saúde e convoca uma rede de profissionais com suas especificidades colocada à disposição da ação resolutiva e com respostas conjuntas para cada situação (Honorato e Pinheiro, 2007). O cuidado nas organizações de saúde, em geral, e no hospital, em particular, é necessariamente multiprofissional, ou seja, depende da conjugação do trabalho de vários profissionais. Este cuidado congrega um grande número de pequenos cuidados parciais que vão se complementando, de maneira mais ou menos consciente e negociada, entre os vários cuidadores que circulam e produzem a vida do hospital. E, no fim, o que caracterizará a maior ou menor integralidade da atenção recebida será a forma como se articulam essas práticas.

Contudo, os mecanismos instituídos de dominação e de relações muito assimétricas de poder entre as várias corporações profissionais dificultam a compreensão por parte dos trabalhadores do quão imprescindível é a colaboração que deve existir entre eles (Cecílio e Merhy, 2003). A fragmentação é um obstáculo à integralidade e, portanto, analisar o trabalho em saúde nesse aspecto, buscando superá-la, significa contribuir para o debate em direção à materialização desse princípio ético e constitucional, entendendo-se que a noção de integralidade está presente em vários níveis das discussões e das práticas na área da saúde. Integralidade inclui questões como o comportamento dos trabalhadores isoladamente, em equipe ou com a rede de serviços, a educação e formação para o trabalho, as políticas públicas e o desenho de um sistema acolhedor que atenda às demandas e necessidades das pessoas, assim como o sentido da defesa da vida, a potencialização dos coletivos e a valorização dos espaços públicos (Louzada, Bonaldi e Barros, 2007; Mattos, 2004). 


\section{Trabalhador da saúde: protagonista na humanização da atenção e gestão} do SUS

Entende-se que estudar o trabalho em equipe na saúde remete a uma discussão sobre sua relevância para a mudança das práticas de atenção e gestão do SUS e o papel de protagonista que o trabalhador da saúde deve assumir no caminho da produção de um SUS humanizado. Instituída em 2003 pelo Ministério da Saúde, a Política Nacional de Humanização da Atenção e Gestão (PNH) do SUS nasceu como uma radicalização da aposta na humanização (Souza e Mendes, 2009).

De acordo com Souza e Mendes, desde sua criação, a PNH gera polêmicas sobre a pertinência do uso desse termo para nomear uma política pública e, sobretudo, sobre os sentidos que tal conceito deve assumir para favorecer e potencializar ações que possam ser consideradas humanizadoras. Isso ocorreria porque, no processo de construção do SUS e mesmo antes da constituição da PNH, o tema da humanização, muitas vezes sob outras denominações, apareceu em vários contextos na busca de melhoria na qualidade da atenção ao usuário e também - mais recentemente - aos trabalhadores da saúde. Porém, essas iniciativas, em sua maioria, eram localizadas ou pontuais, estruturadas a partir de concepções variadas e de intenções e enfoques específicos, além de carregar como obstáculos a sua legitimidade, a fragmentação, a disparidade de perspectivas e, até mesmo, sua fragilidade conceitual e metodológica.

A humanização adotada pela PNH é assumida não como um programa isolado, mas como política pública que pretende ser transversal na Rede SUS e para além do Estado, ultrapassando as fronteiras dos diferentes núcleos de saber/poder que se ocupam da produção da saúde, abarcando um conjunto de princípios e diretrizes que se traduzem em ações nos diversos serviços, nas práticas de saúde e nas instâncias do sistema, caracterizando uma construção coletiva que considera que sujeitos sociais, quando mobilizados, são capazes de transformar realidades, transformando-se a si próprios neste mesmo processo (Brasil, 2004).

Para Souza e Mendes (2009, p. 683), a humanização envolve o refletir e o agir sobre "modos de pertencer e de circular no plano institucional, nas relações interprofissionais e com os usuários", permitindo rever a pertinência e a atualidade de nossos saberes, atitudes, de nossas formas de "ser-emgrupo" e de "fazer com o outro".

Já Pedroso e Vieira (2009) afirmam que a humanização do SUS indica mudanças nas práticas de atenção e gestão com uma aposta nos sujeitos concretos, enquanto novos homens em interação e que constroem em conjunto novas práticas de saúde em defesa da vida. E acrescentam que, para fortalecer o "SUS que dá certo", é necessário enfrentar os modos de produção de 
saúde que caminham na direção oposta à defesa da vida, como os que utilizam a normalização rígida dos processos de organização de serviços e de definição do acesso, os modos de cuidar centrados na doença, na queixa, e os modos de trabalhar que, por vezes, destituem a capacidade de decidir e possibilidades de participação dos sujeitos.

A PNH preconiza o fortalecimento do trabalho em equipe multiprofissional, fomentando a transversalidade e a grupalidade, o apoio à construção de redes cooperativas solidárias e comprometidas com a produção de saúde e de sujeitos e coletivos implicados na rede SUS, na construção de autonomia e protagonismo desses sujeitos e, consequentemente, na sua corresponsabilidade nos processos de gestão e atenção. A PNH apresenta algumas diretrizes, dispositivos e ofertas metodológicas, tais como acolhimento, clínica ampliada, equipe de referência/apoio matricial, projeto terapêutico singular, valorização dos trabalhadores da saúde, formação de redes, visita aberta e direito a acompanhante, bem como a implementação de cursos de formação, câmaras técnicas e comitês de humanização nos locais de trabalho (Brasil, 2004).

Em suma, a humanização não se limita à emergência de novas propostas. Trata-se, na verdade, de uma estratégia de valorização das práticas de gestão e de atenção que já ocorrem no dia a dia dos serviços, buscando romper o abismo entre a tradicional normatização e prescrição do aparato burocrático do Estado e o agir concreto na experiência cotidiana de produzir saúde. Ao fomentar movimentos de lateralidade e transversalidade entre sujeitos, espera-se fazer circular saberes e poderes, alterando o padrão organizacional e de gestão verticalizados e hierarquizados, visando a melhorar os processos comunicacionais. Para a $\mathrm{PNH}$, a produção de saúde se dá por meio de encontros, a partir das relações entre sujeitos na construção de contratos terapêuticos que possam servir à qualificação da vida, bem como na ampliação dos sentidos do trabalho em saúde que produzam sujeitos mais livres e autônomos (Pasche, Passos e Hennington, 2010).

\section{Percurso metodológico}

\section{A perspectiva ergológica como referencial teórico-metodológico da pesquisa}

A perspectiva ergológica proposta pelo filósofo francês Yves Schwartz foi utilizada como referencial teórico-metodológico na pesquisa em foco. Ela é fundada no desconforto intelectual suscitado pela constatação de que toda atividade de trabalho é atravessada pela história e ao mesmo tempo fabricante dela. Os produtos da história estão cristalizados nos conhecimentos 
acionados, nos sistemas produtivos, tecnologias, formas de organização, procedimentos e nas relações sociais que se entrelaçam e opõem os homens entre si (Schwartz, 2003). Porém, todas essas normas, saberes, esse conjunto de concentrados de história passada, que são denominadas na ergologia como normas antecedentes, não determinam por si sós o que vai se passar na atividade de trabalho. Este conjunto de história sedimentada na rigidez e na exaustão das prescrições do trabalho pode antecipar somente em parte o que vai se produzir no vivo da atividade, pois nenhuma atividade é mera execução, ou mera repetição de sequências de operações previstas por outros e antecipadas. Toda atividade é sempre ressingularização ou uma renormalização parcial em torno de si (Schwartz, 2003; Schwartz, Duc e Durrive, 2007a).

A atividade compreende tudo aquilo que deve ser ajustado, rearranjado, inventado pelos trabalhadores e, por isso, o trabalho é sempre variável e imprevisto, de alguma forma infiel, e são os trabalhadores que devem dar conta desta infidelidade através da mobilização de suas capacidades e escolhas, o que faz com que o mesmo seja mais do que uma mera execução, mas uso de si (Schwartz, 2000). Assim, toda atividade é sempre um uso de si, "por si mesmo", devido às escolhas, às arbitragens feitas no "vazio de normas", e uso de si "pelos outros" (Schwartz, 2006; Schwartz, Duc e Durrive, 2007b). A negociação dos usos de si é sempre problemática e por isso diz-se que a atividade é sempre o lugar de uma "dramática". Dessa forma, para compreender a complexidade da atividade, a perspectiva ergológica se interessa pelo trabalho real, pelo vivido em situação de trabalho (Schwartz, Duc e Durrive, 2007c).

Com base na perspectiva ergológica, Hennington (2008) afirma que, apesar das várias tentativas de estabelecer protocolos e regras comuns na área da saúde, não é possível alcançar a total padronização das práticas. Afinal, o cotidiano exige que os trabalhadores arbitrem e façam escolhas diante das diversas situações e, assim, eles pensam e se pensam e vão construindo novas realidades. Para se aproximar do trabalho real em saúde, é preciso chegar o mais próximo possível da atividade, para avaliá-la e reconhecê-la como ela é, e para tal é preciso reconhecer a existência destes espaços de microtransgressões e rupturas com o que está prescrito.

Quanto à dimensão coletiva do trabalho, Schwartz, Duc e Durrive (2007a) apresentam a ideia das entidades coletivas relativamente pertinentes (ECRP) como uma maneira diferente de abordar os processos de cooperação efetivados em toda atividade, tal como o trabalho em equipe na saúde. Este conceito tem duas principais características: a mais importante é que as ECRP se distanciam de qualquer organograma ou qualquer outro tipo de predefinição de lugares. Portanto, uma ECRP não se forma num coletivo predefinido, pois suas fronteiras são as da atividade. Outra característica é que elas existem em toda atividade humana e simplesmente se constroem 
no dia a dia da vida das pessoas e em função de certo conjunto de preocupações comuns. As ECRP são 'entidades' no sentido de que existem fronteiras invisíveis que reúnem pessoas que se conhecem, mas podem pertencer a espaços institucionais diferentes; são 'coletivas' na medida em que nas ECRP circulam informações em todos os sentidos e pelas vias mais diversas; e são 'relativamente pertinentes', pois são apropriadas para a compreensão de como as coisas andam, mas só relativamente, já que suas fronteiras são variáveis, mudam em função das pessoas e dos processos.

O trabalho em equipe de saúde pode configurar-se nos serviços como um espaço formal e institucionalizado e, muitas vezes, prescrito ou pode conformar-se na fluidez dos encontros e das necessidades e demandas de atenção à saúde. O agrupamento de profissionais de saúde, num certo local e num dado momento, não necessariamente constitui 'trabalho em equipe'. Muitas vezes, o trabalho em equipe revela-se em cenários e por meio de práticas - não totalmente isentas mas distantes de prescrição ou normas disciplinares - baseado no encontro de distintos sujeitos com diferentes histórias, formações e experiências, numa aproximação da perspectiva transdisciplinar de construção de um novo saber.

\section{Sujeitos de pesquisa e critérios de seleção}

Os sujeitos da pesquisa foram trabalhadores da saúde de nível universitário e com tempo de serviço na instituição superior a um ano que atuavam no setor de internação do instituto. Totalizaram 69 profissionais: 31 médicos (incluindo médicos-residentes), 14 enfermeiros, 9 fisioterapeutas, 5 psicólogos, 4 farmacêuticos, 3 nuricionistas, 3 assistentes sociais. Foram excluídos aqueles que não participavam diretamente da assistência e os que trabalhavam somente em regime de plantão noturno ou nos finais de semana, caracterizando uma amostra por conveniência. O período escolhido para a realização das observações foi o da manhã, já que era o período em que todos os profissionais concentravam seu maior volume de atividades na internação.

Após autorização por parte da coordenação do Centro Hospitalar do instituto - formado pela internação, ambulatório e hospital-dia -, o projeto de pesquisa foi submetido aos comitês de ética em pesquisa da Escola Nacional de Saúde Pública Sergio Arouca (Ensp) e do Ipec, duas unidades da Fiocruz. Após aprovação, foi apresentado ao conjunto de profissionais do setor e nesse momento foi entregue cópia do termo de consentimento livre e esclarecido (TCLE) com informações detalhadas sobre a pesquisa e contatos da pesquisadora responsável. Posteriormente foram agendadas as entrevistas com aqueles que concordaram em participar e assinaram o TCLE. Dos 41 profissionais convidados, 29 aceitaram participar da pesquisa, e deste total 23 foram entrevistados. 
A pesquisa qualitativa realizada utilizou como técnicas de produção de dados entrevistas semiestruturadas e observação participante. As observações seguiram um roteiro-guia e foram divididas em: sete sessões de três horas de observação da rotina por grupo profissional; 13 sessões de duas a três horas de observação de situações potenciais de trabalho em equipe; e observação das reuniões de equipe, cinco na Unidade de Terapia Intensiva (UTI) e apenas duas na enfermaria. As entrevistas, seguindo também um roteiro, ocorreram em sala reservada previamente nas dependências da internação ou nos quartos de descanso médico e de enfermagem. No total foram 23 profissionais entrevistados - quatro médicos infectologistas, dois intensivistas, quatro fisioterapeutas, duas nutricionistas, três psicólogas, duas assistentes sociais e seis enfermeiros. Apesar do aceite inicial de 29 trabalhadores em participar da entrevista, numerosas tentativas de agendamento sem sucesso acabaram levando à eliminação de seis profissionais do quadro de possíveis entrevistados. As entrevistas duraram de dez a 60 minutos, e o trabalho de campo (entrevistas e observações) ocorreu no período de abril a junho de 2010.

A análise do material empírico utilizou como referencial a análise de conteúdo, na sua vertente análise temática (Minayo, 2008). Para proteger a identidade dos participantes optou-se pelo uso de siglas (AS - assistente social; E - enfermeiro; F - fisioterapeuta; $\mathrm{M}$ - médico; N - nutricionista; $\mathrm{P}$ - psicóloga), seguidas de um número para cada profissional diferente dentro de sua área. Ao constatar que dos 23 entrevistados, 18 eram do sexo feminino, decidimos nos referir aos profissionais sempre no feminino, com exceção dos médicos, que foram mencionados sempre no masculino, dada a igual quantidade de profissionais dos dois sexos.

As categorias analíticas da pesquisa foram assim definidas: 'relações interprofissionais': 'interdependência e fragmentação'; 'complementaridade instrumental'; '(re)conhecimento do trabalho alheio'; 'o outro como sujeito da mudança'; 'trabalho em equipe em construção'; 'trabalho em equipe: dificuldades e propostas'.

\section{Resultados e discussão}

Os resultados aqui apresentados são relativos ao estudo da rotina na internação do Centro Hospitalar do Ipec e, especialmente, das reuniões multiprofissionais, com enfoque nas relações entre os profissionais do setor.

\section{O cenário do estudo}

O Ipec tem a missão de contribuir para a melhoria das condições de saúde da população brasileira através de ações integradas de pesquisa clínica, 
desenvolvimento tecnológico, ensino e assistência de referência na área de doenças. O instituto tem sua origem no início do século passado a partir da construção do Hospital de Manguinhos, planejado pelo próprio Oswaldo Cruz e finalizado em 1918, um ano após sua morte. Foi o primeiro e único hospital do país concebido com o objetivo de desenvolver pesquisas científicas. Em 1986, sofreu um importante processo de reestruturação e revisão de sua missão a partir de um projeto de desenvolvimento da pesquisa clínica multiprofissional. Com as denominações sucessivas de Hospital de Manguinhos, Hospital Oswaldo Cruz e Hospital Evandro Chagas, em 1999 tornou-se uma unidade técnico-científica da Fiocruz com a denominação de Centro de Pesquisa Hospital Evandro Chagas. Em 2002, passou a Instituto de Pesquisa Clínica Evandro Chagas e, recentemente, foi definido pela portaria n. 4.160 de dezembro de 2010 do Ministério da Saúde (MS) como Instituto Nacional de Infectologia, devendo atuar como órgão auxiliar do MS na formulação de políticas públicas, no planejamento, desenvolvimento, coordenação e avaliação das ações integradas para a saúde na área da infectologia (www.ipec.fiocruz.br/cgi/cgilua.exe/sys/start.htm?tpl=home).

Além de desenvolver pesquisas e atividades assistenciais, o instituto tem um programa de pós-graduação stricto sensu em Pesquisa Clínica de Doenças Infecciosas e desenvolve diversos cursos lato sensu, residência médica, cursos de especialização e capacitação, contribuindo para o aperfeiçoamento da força de trabalho do SUS. É hospital de referência para HIV/Aids, leishmaniose, dengue, micose sistêmica, doença respiratória aguda grave, doença causada pelo HTLV, dentre outras, e também para diagnóstico histopatológico em doenças infecciosas. É credenciado pela Agência Nacional de Vigilância Sanitária (Anvisa) para realização de ensaios de bioequivalência/biodisponibilidade.

O setor de internação do Centro Hospitalar do Ipec, local de realização da pesquisa, divide-se em 25 leitos de enfermaria e quatro de UTI. Há ainda uma sala de procedimentos que, em situações especiais, é utilizada como leito de enfermaria ou de UTI e uma sala de prescrição, local em ficam os computadores e os diferentes profissionais se encontram, verificam os prontuários e fazem as anotações. Por ocupar um prédio tombado pelo Patrimônio Histórico, este não pode sofrer grandes reformas ou alterações da fachada e apresenta problemas de falta de espaço e de ambiência em geral. Não existe uma sala de reuniões no local, e as reuniões de equipe acontecem de maneira improvisada, muitas vezes não há como sentar.

Na internação cada usuário possui um prontuário do tipo fichário com evolução e prescrições relativas a todas as categorias profissionais que prestam assistência, com divisórias e anotações separadas pelas áreas profissionais.

As reuniões multiprofissionais observadas ocorreram na enfermaria/sala de prescrição e na UTI. O número reduzido de reuniões presenciadas durante 
o estudo deveu-se ao fato de que as reuniões de equipe não eram situações já consolidadas e usualmente ocorriam por iniciativa de alguns profissionais envolvidos, carecendo de regularidade. As reuniões acompanhadas na UTI tiveram maior frequência e regularidade, enquanto na enfermaria eram praticamente inexistentes, havendo tentativas de retorno durante o período do trabalho de campo.

As reuniões na UTI costumavam ocorrer a partir da iniciativa de um dos médicos intensivistas, pela manhã, após o término das intervenções de todos os profissionais, e pouco antes do horário das visitas familiares. Era considerada uma reunião de rotina entre alguns profissionais, em especial, os médicos (intensivista e residente), enfermeiros, nutricionistas e fisioterapeutas, porém quase desconhecida por parte de outros, como as psicólogas, farmacêuticos e assistentes sociais. Apesar de alguns profissionais demonstrarem não ter conhecimento desses encontros, outros relataram ter participado pelo menos alguma vez.

Você está falando que é no final da manhã, que está acontecendo (...). Eu já passei, já vi os pacientes, já não estou mais lá no CTI... eles não vieram pra chamar... eu acho que não é rotina, deve ter também alguma coisa de (...) como se não modificasse muito (...) a gente estar aqui (...). Mas é um CTI, né? O paciente está em coma, o que psicólogo vai falar? Tem uma família... e às vezes a gente tem essa ideia de que psicólogo vai atender paciente no CTI se ele tiver consciente (...). Mas eu acho assim, se eu tiver passando por lá e tiver um paciente e eu ficar, eles também não vão me mandar embora (P2).

Há pelo menos dois pontos a ressaltar nessa fala da psicóloga: o desconhecimento quanto à existência da reunião e o sentimento de não ter reconhecida a importância de seu trabalho naquele setor, considerado necessário apenas nos casos em que o paciente internado apresenta-se "consciente".

Semelhante a uma passagem de plantão tradicional, na dinâmica da reunião, as condutas a serem realizadas eram colocadas em pauta, debatidas, revistas e definidas, em sua maior parte em conjunto, solicitando-se a participação de todos os presentes. A discussão se dava em torno de um banco de dados computadorizado sobre qualidade do atendimento na UTI que era alimentado pelas informações obtidas durante as reuniões. O preenchimento desse banco de dados guiava a discussão, sob a coordenação do profissional médico, com abertura para a intervenção dos demais profissionais em qualquer momento.

Jacob Filho e Sitta (2002), ao tratarem da interprofissionalidade na gerontologia, consideram as reuniões de equipe absolutamente necessárias, pois os contatos informais entre os profissionais podem e devem acontecer. Entretanto, é fundamental que haja um momento da equipe, de preferência 
com data, local, duração e frequência preestabelecidos, em que todos possam tornar públicos seus problemas com o usuário ou com relação ao grupo, possibilitando, assim, aos demais membros participar tanto do diagnóstico quanto da proposta de intervenção. As reuniões de equipe cotidianas funcionam como dispositivos de estruturação, organização, informação, estabelecimento de diretrizes e espaço de decisão. É uma oportunidade para socialização do conhecimento, planejamento conjunto e subsídios para tomadas de decisões mais acertadas (Grando e Dall' Agnol, 2010).

De modo geral, o profissional médico ou o residente iniciava a reunião, relatando os casos clínicos dos usuários, um a um, na ordem numérica de seus leitos. Os aspectos clínicos eram apresentados para todos os presentes, restringindo-se apenas aos profissionais médicos em alguns momentos mais específicos, em que a discussão se aprofundava em relação ao diagnóstico ou ao tratamento medicamentoso. O round era usualmente guiado pelo médico, que era o centro da reunião e responsável por todas as decisões finais, porém havia abertura para os outros profissionais expressarem suas opiniões, sugestões, questionamentos, que eram analisados pelo médico e considerados para a tomada da decisão.

É um protocolo, que participa o médico, o staff e residente, enfermeiro, o... às vezes, assistente social e nutricionista... Geralmente, é (...) quando está terminando, o médico termina de imprimir as prescrições, a gente 'apraza' (...), aí começa o round. (...) Eu acho que aqui (...) é uma equipe em que todos têm liberdade (...). Dão essa liberdade pra todo mundo assim... Se tiver que falar alguma coisa, dar uma opinião, não tem problema não (E2).

Eu participei do round da UTI, foi num momento que eu estava acompanhando esse paciente que estava na UTI (...). Foi muito interessante, porque a equipe é menor (...). Tinham dois enfermeiros, um técnico, um médico, a fisioterapeuta, nutricionista, e eu pude participar, (...) e às vezes o serviço social, então houve uma integração muito boa (...). O médico é que estava conduzindo esse round e era abordado assim as dificuldades: 'o paciente não está urinando, o que a gente pode fazer? Vamos botar sonda?'. Então, alternativas... (...) Todos se colocavam... todos... bem à vontade (...). Quando havia um comentário, havia uma escuta desses comentários e assim uma atenção a esses comentários... uma reflexão... muito bom, muito bom (P3).

A participação dos profissionais de outras categoriais era considerada importante pelo médico que coordenava a reunião, porém eram raros os momentos em que intervinham espontaneamente, restringindo-se a responder às informações solicitadas pelo médico. Quanto às ações dos profissionais não médicos, as questões eram colocadas para discussão pelo 
médico, eles se manifestavam a favor ou contra determinada conduta ou alteração. Suas ponderações eram ouvidas, mas quem tomava a decisão acabava sendo o profissional médico, que podia ser a favor ou contra o que propôs o outro profissional.

Todas essas situações retratam momentos de subordinação dos profissionais não médicos ao profissional médico, que, de certo modo, reduzia-lhes a autonomia ao tomar para si o poder de decisão final. Percebeu-se que a reunião era conduzida pela normatividade médica e os outros profissionais se submetiam, reiterando e compartilhando a desigualdade e a subordinação hierárquica. O profissional médico coordenava o round com objetivo de checar todos os passos e condutas, e o espaço para os demais profissionais era visto como cedido pelo médico e, por isso, geralmente as participações ocorriam a partir da sua solicitação.

Um round que eu gosto muito que seja o mais multidisciplinar possível. Aqui no Ipec em geral o que eu consigo mesmo... a enfermagem e fisioterapia... a nutrição, como eu sempre chamo, elas acabam vindo, mas não é uma coisa assim tão... e elas participam bastante porque elas já sabem o que eu vou perguntar. Mesmo que elas não estejam no round, em geral elas falam comigo... existe uma comunicação boa. (...) E aquilo tem um objetivo 'tocativo', tanto é que você vê que atualmente eu passo o round lá botando no computador aqueles dados, porque aquilo é um banco de dados. Então, primeiro tem o checklist, que é a checagem de cada coisa... O objetivo é esse mesmo. (...) Estar lembrando todas as coisas detalhadamente e dar oportunidade da enfermeira falar algum problema que ela viu e que ninguém viu, dar oportunidade pra fisioterapia também, eu acho que tudo aqui é muito, muito enriquecedor (M5).

O round do CTI (...) é muito mais forte na parte médica (...). Medicamento que está fazendo, medicamento que vai suspender, diagnóstico se está fechado ou se (...) não está fechado. E aí, com relação à nutrição, é se está atingindo valor calórico necessário ou não... ponto, fica por aí. A gente não discute (...) por que aquele paciente não está atingindo suas necessidades, e aí necessidades de uma forma (...) não é só valor calórico (...). A gente fica muito fechado, muito focado. Até pelo tempo mesmo, assim... é muito corrido (N2).

Percebe-se que não há nessa dinâmica de atenção a perspectiva de uma clínica ampliada ou construção conjunta de projetos terapêuticos singulares, pois, apesar de existir um espaço de reunião, com certa regularidade e abertura para participação de todos, a assistência não era organizada por equipe de referência. Além disso, a forma como os profissionais não médicos se colocavam nas reuniões de equipe reitera a subordinação ao profissional médico, pois eles abriam mão de sua autonomia técnica, deixando o 
encaminhamento dos casos e a decisão com o médico ou permitindo que predominasse uma relação instrumental (Peduzzi, 2007).

Já na enfermaria, havia dois tipos de reuniões: as realizadas entre os membros de uma mesma equipe profissional para passagem dos casos e as multiprofissionais, com a apresentação e discussão de casos com a participação de profissionais de todas as áreas.

No início da pesquisa, as reuniões da equipe médica não ocorreram com regularidade, porém, na fase final, por iniciativa dos médicos, começou um movimento para realizá-las, com a discussão apenas de casos selecionados dentre os mais graves e abertura para a participação dos profissionais de todas as áreas.

Devido à informalidade da reunião multiprofissional, esta ocorria em torno da questão médica e a partir das demandas surgidas durante a discussão. As opiniões ou informações a respeito das intervenções de outros profissionais eram solicitadas, mas a presença destes não era obrigatória e não havia nenhuma comunicação formal sobre as reuniões. Os médicos solicitavam a presença de determinados profissionais, entretanto, a maioria dos profissionais não médicos relatou não ter sido comunicada a priori. A participação em alguma reunião foi decorrente do simples fato de estar "passando por ali" quando percebeu o que estava acontecendo e "resolveu ficar".

Antes do início da pesquisa se realizava uma reunião multiprofissional instituída pela direção da internação, que seguia os moldes de um round médico, em que se discutiam todos os usuários internados, com a garantia de participação de profissionais de todas as áreas. Havia uma convocação formal à participação de todos e, segundo os relatos, este tipo de encontro foi extinto por ocasião de mudança na gestão do Centro Hospitalar e, desde então, as reuniões consideradas multiprofissionais foram as citadas anteriormente, em que a participação dos profissionais não médicos ocorria em meio à reunião dos médicos e dependia exclusivamente da sua disponibilidade e interesse.

Assim que eu cheguei aqui tinha uma coisa que era toda semana, era um round, (...) que é uma reunião na própria sala de prescrição, onde liam o quadro e iam falando de cada paciente de acordo com o quadro de internação (...). Os outros profissionais falavam à medida que havia necessidade, em relação à nutrição, assistente social, psicologia. (...) Depois mudou a direção... aí (...) a direção da parte de internação (...) ficou de assumir (...). Aí retornou, mas retornou de uma forma diferente, misturou muita coisa, aí acharam que não estava dando certo, desde cadeira quebrada, desde comida que ficava exposta, até a situação do paciente, não gostaram porque demorava muito (...) aí foi dada uma parada. Posteriormente, (...) ficou esse vácuo (...), então os médicos começaram a se reunir, mas com uma coisa só clínica, quem estava na sala que quisesse participar participava, mas não 
foi nada formalizado. Agora eu percebo que está tendo, não se sabe o dia ao certo, acho que quando eles têm disponibilidade de tempo, eu percebi que não estão fazendo mais... falando do paciente individual de acordo com o quadro, mas sim dos pacientes que chamaram atenção por alguma coisa, que teve algum problema mais... e que eles querem que discuta. (...) Não foi formalizado nada assim específico... 'ah, vai ter round', é quando aparecem as situações eles se reúnem ali, e quem quiser a princípio ficar lá, escutando, pode escutar. Se quiser perguntar também pode, não tem nenhum impedimento não (AS1).

Para humanizar a atenção é preciso que haja um modelo de gestão que se paute nas decisões coletivas e na democratização das relações de trabalho, inclusive criando espaços coletivos de discussão que permitam o envolvimento dos trabalhadores nas decisões sobre seus processos de trabalho, entendendo que atenção e gestão são indissociáveis e que, ao fomentar o protagonismo, a corresponsabilidade e a autonomia dos sujeitos e dos coletivos, as ações de gestão e atenção serão mais efetivas (Brasil, 2008). Decisões e mudanças devem ser fruto do trabalho em equipe, e a perspectiva da humanização busca garantir que o poder seja compartilhado por meio de análises, decisões e avaliações construídas coletivamente, já que considera que a gestão é realizada por todos os envolvidos na produção de saúde, rompendo o modelo taylorizado de separação entre quem pensa/planeja/avalia e quem executa. Cabe lembrar que a humanização não é um estado de coisas, e sim reflexo de práticas cotidianas nos serviços pautadas na indissociabilidade atenção-gestão (Brasil, 2009b).

$\mathrm{Na}$ internação, as reuniões observadas, ditas multiprofissionais, foram, na verdade, reuniões médicas com a presença de profissionais de outras áreas, que geralmente participavam através da escuta e limitada intervenção, o que ocorria principalmente quando demandados. Isto porque, apesar da abertura, o que predominava era a discussão com nítida centralidade médica. O médico passava os casos e realizava a reunião da maneira convencional, com a diferença de que, se outros trabalhadores estivessem presentes, surgindo necessidade de complementação, estes eram chamados a opinar e, mais frequentemente, a fornecer informações úteis à resolução do caso, numa relação instrumental, tal qual refere Peduzzi (2007).

Nesse contexto, os profissionais não médicos apresentavam diversas queixas quanto à organização da reunião e à centralidade da discussão médica focada no diagnóstico e tratamento, o que revela a necessidade de reorganizar o processo de trabalho e de fomentar a discussão dos problemas de saúde na perspectiva da 'clínica ampliada'. Esta diretriz da PNH sugere que há por parte dos profissionais uma compreensão abrangente do processo saúde-doença, incluindo aspectos subjetivos e o contexto socioeconômico e cultural; a construção compartilhada de diagnóstico e terapêutica; 
o foco do trabalho na pessoa e não nos procedimentos; a comunicação transversal em vez da instrumental; e a criação de instrumentos de suporte e apoio para que os trabalhadores possam lidar com as dificuldades referentes à atenção em saúde e as diversas situações que se apresentam (Brasil, 2009a).

A PNH problematiza que a fragmentação do processo de trabalho entre os diferentes profissionais com distintos olhares produz uma progressiva redução do objeto de trabalho, a individualização e a desresponsabilização da atenção e do cuidado. Neste contexto, a diretriz da clínica ampliada funciona como uma ferramenta de articulação e inclusão dos diversos enfoques. Tal proposta, realizada por meio do atendimento conjunto e/ou da discussão de casos e formulação de projetos terapêuticos singulares, aliada aos dispositivos de 'equipe de referência' - conjunto de profissionais que se responsabiliza pelos mesmos usuários cotidianamente - e de 'apoio matricial', com a disponibilização de recursos especializados, podem contribuir muito para a superação da racionalidade gerencial tradicionalmente verticalizada, compartimentalizada e produtora de processo de trabalho fragmentado e alienante (Brasil, 2009a).

Nessa direção, a PNH destaca que trabalhadores, gestores e usuários devem formar um pacto de corresponsabilidade e propõe como diretriz a cogestão, um modelo centrado no trabalho em equipe, na construção coletiva, em espaços coletivos que garantam que o poder seja compartilhado, percebendo a gestão não como um campo de ação exclusiva de especialistas, mas considerando que todos os sujeitos envolvidos na produção da saúde fazem gestão (Brasil, 2009b).

Apesar de alguns profissionais perceberem e expressarem o caráter instrumental das reuniões que ocorriam no setor de internação, criticando muitas vezes a postura do médico na orientação desses encontros, muitos acreditavam que a iniciativa de transformá-las num espaço multiprofissional deveria ser mesmo do médico, num posicionamento aparentemente contraditório, que pode ser entendido como uma mistura de submissão e valorização do saber médico e reconhecimento de seu poder de liderança.

Eu acho que o round aqui assim... acontece... mas eu acho que deveria ser assim... isso teria que ser uma rotina. Tipo assim... se os médicos que fazem o round não estão presentes, estão em reunião ou em congresso, teria que ter um outro pra fazer isso, até mesmo o residente. Eu acho que o residente também está ali olhando o cliente, o paciente, então acho que tem que reunir a equipe e dar continuidade nesse papel, que é o papel da medicina (E2).

A gente participou algumas vezes, mas eu não vi ninguém multidisciplinar lá... Eu só via médico falando, entendeu? E no máximo alguém escutando... Eu acho que assim é difícil, mas se você vai estimulando... Tanto é que você vê... Hoje em dia, 
eu percebo, às vezes eu estou meio sem saco, nem quero passar round... mas as pessoas..., entendeu? 'Vai ter round?' Elas me cobram, elas gostam, entendeu? A própria enfermagem, a fisioterapia gosta... (M5).

Outras falas revelam parte do que causava a atitude quase passiva dos profissionais não médicos nas reuniões: a sensação de que só deveriam intervir se o que tivessem a manifestar pudesse ser visto pelos médicos como relevante para a discussão.

Se você acha que tem alguma coisa que eles estão falando que você pode acrescentar, você fica à vontade, eles vão ouvir numa boa, mas se você acha que não tem nada a acrescentar em relação ao paciente, não tem porque você parar uma discussão de um paciente pra não incluir nada... (E4).

Os médicos falam a questão mais clínica, aí de vez em quando surge um comentário que tem a ver com o serviço social ou outra especialidade, eles (...) pediam nossa opinião ou então a gente falava o que a gente queria falar (...). Quando ele levantava alguma questão social, eu achava, eu falava, mas tinha outros casos que eu não sentia assim (...) poderia não ser relevante (AS2).

Ficam evidentes as dificuldades para a concretização de um efetivo trabalho em equipe vivenciadas por esses profissionais, e é preciso perceber o movimento e a dimensão gestionária dessas situações de trabalho. Os profissionais não médicos eram chamados a participar das reuniões médicas, demonstrando certa abertura num cenário em que a racionalidade vigente operava na atividade e relações, no sentido de consolidar a centralidade médica e o isolamento das áreas profissionais. Entretanto, eles permaneciam em posição periférica na discussão e isso gerava descontentamento e sensação de que faltava conhecimento de suas atribuições e de reconhecimento do valor de sua fala e do seu fazer. Os profissionais se viam diante de um debate de normas e valores, entre a vontade de participar da reunião e ter suas contribuições valorizadas e reconhecidas, desenvolvendo efetivamente um trabalho em equipe, e uma postura tímida ou passiva, reforçada pelo formato da reunião centrado na figura do médico, que gerava muitas vezes um sentimento de resignação ou de impotência em relação a essa norma antecedente aparentemente rígida e difícil de romper, que é expressa pela racionalidade biomédica, orientadora das ações e práticas nos ambientes de prestação de cuidado.

É importante destacar que certamente existe um debate de normas e valores que o trabalhador enfrenta diante das infidelidades que se apresentam na situação de trabalho quando se afirma que sua atitude na reunião demonstra certa passividade. A aparente passividade do profissional não 
médico se revela como consequência desse debate, que o leva muitas vezes a optar pela não intervenção durante a reunião, talvez por comodismo ou numa tentativa de se preservar e de não se expor. Trata-se de compreender que essa postura não acontece sem um esforço desses profissionais, mas decorre de suas escolhas frente ao que Schwartz denominaria "dramática dos usos de si".

Alguns relatos evidenciam uma dificuldade grande de participação, por exemplo, das profissionais de psicologia e serviço social, cujas abordagens sobre o objeto de trabalho se diferenciam da racionalidade biomédica e, por isto, muitas vezes desistiam de colocar algo que para elas era relevante, acreditando que para os outros não faria sentido. Tal postura não era exclusiva dessas áreas e representa a maneira que esses profissionais não médicos escolheram para enfrentar essas situações.

$\mathrm{Na}$ época que eu entrei aqui, era oficial, todo mundo ficava aqui, vinha até farmacêutico, mas também era uma forma, não sei (...). A mim particularmente incomodava, porque, embora todos os profissionais ficassem ali, a forma da direção do round era muito médica (...). Eles discutiam e tal, e quando a gente falava alguma coisa, 'ah, está bom... já sabemos... está legal... e aí vamos embora, ah, o segundo paciente...'. Então, não tinha uma (...) proximidade mesmo das diversidades do discurso, aí (...) a participação dos outros profissionais era mais quando demandavam ou quando a gente achava que tinha alguma coisa... (P2).

Round aqui é médico, quem tiver e que quiser ficar pode ficar, se você for falar... dependendo do que você falar vai ser bem-vindo ou vai ser mal vindo, né?! Não deveria ser assim, o round é da equipe, a equipe vai falar o que tiver que falar. O paciente está sendo cuidado por todos, né? Mas aqui não é assim (...), aqui é discussão médica, entendeu? (P1).

A pesquisa indicou que o que contribui de forma decisiva para que esses espaços de reunião fiquem distantes da proposta de trabalho em equipe é a racionalidade que os fundamenta. Entretanto, vale destacar que o marco biomédico não é exclusivo da corporação médica e fica evidente nas ações e práticas de outros profissionais de saúde. Por exemplo, apesar de alguns profissionais não médicos considerarem necessária uma atitude de humildade, além da mudança de postura dos médicos durante os rounds, dividindo a reunião igualmente entre os profissionais, com espaços de fala bem delimitados para cada área profissional, tal forma de conduzir a reunião é sustentada pela mesma lógica e apenas transportaria a fragmentação do serviço para as reuniões.

Observa-se também que existia permeabilidade por parte dos profissionais médicos às propostas de mudanças no processo de trabalho, porém 
encontravam-se aparentemente 'presos' da mesma forma à racionalidade que comanda suas práticas e, portanto, à forma habitual de se reunir e orientar a discussão de casos e de construir propostas de assistência.

No início, acho que a gente tinha muita dificuldade porque, como era uma coisa que era relativamente nova aqui, então muitos profissionais (...) levavam questões que não eram pra ser passadas naquele momento, mas provavelmente porque não tem essa cultura de você fazer sempre. É uma questão de hábito mesmo. Quem faz round geralmente são as equipes de médico e de enfermagem por causa da questão de você passar o plantão. Então, assim, desde que a gente está na faculdade, a gente é habituado a, num espaço de três minutos, passar tudo o que é o mais relevante pro paciente. Então, assim, o serviço de psicologia ou, às vezes, o serviço de nutrição ou outros serviços que às vezes participam não têm, eu acho que não têm (...) [não] é o hábito deles... (M3).

A gente está tentando agora, já tem umas duas semanas que a gente conseguiu colocar de novo o round, então (...) a gente discute os casos, assim, que merecem mais atenção, em algum aspecto (...). Aí a gente chama, a gente tem chamado, a expectativa é que o pessoal (...), o ideal seria que todos participassem (...). Mas eu acho que existe a vontade do pessoal de participar. Eles ficam meio (...) à parte da discussão, também a discussão fala muito do aspecto médico, é aí.... fica aquela coisa (...). Mas, às vezes, o aspecto médico nem é o principal, né, às vezes uma questão social [é] mais importante... (M2).

O dispositivo 'projeto terapêutico singular', uma variação da discussão de caso clínico - em que a toda a equipe se reúne e todas as opiniões são vistas com igual importância, na busca do entendimento da demanda de cuidado em saúde do usuário e da construção conjunta de propostas de intervenção -, exige da equipe abertura ao imprevisível e ao novo, aprendendo a lidar com a possível ansiedade trazida pela proposta. É necessário também tomar o cuidado de não permitir que as reuniões de equipe sejam utilizadas para a simples distribuição de tarefas, elas devem constituir espaços de diálogo em um clima favorável para que todos tenham direito à voz e à opinião, um espaço fraterno para a troca de ideias, incluindo as críticas. Criar esse ambiente, aliado à objetividade nas reuniões, exige aprendizado, além disso, é preciso que haja um clima de liberdade de pensar o novo (Brasil, 2009a).

Há dificuldades de se criar uma forma de reunião de equipe em que todos os profissionais participem democraticamente na construção de projetos terapêuticos para os usuários. A racionalidade biomédica funciona como uma norma antecedente que perpassa todas as práticas e faz com que a todo o momento o trabalhador se veja diante de um debate de normas. Existe um formato já consagrado no modelo biomédico de se reunir para discutir 
'os casos' a partir da visão médica, porém as demandas e necessidades dos usuários exigem um tipo de reunião em equipe e de intervenção que deve ultrapassar o modelo prescrito. Ou seja, é preciso reinventar a maneira de profissionais de áreas diferentes se reunirem para discutir as necessidades dos usuários e construírem 'juntos' projetos terapêuticos.

Evidenciou-se ainda durante a pesquisa, que havia um posicionamento por parte da gestão do serviço de que as reuniões multiprofissionais deveriam ser definidas depois que as reuniões médicas estivessem ocorrendo plenamente, estabelecendo-se uma priorização e uma distinção entre a reunião médica e a multiprofissional. Essa separação foi questionada por alguns profissionais não médicos, alegando-se que tal separação revelava que o médico se colocava como não pertencente à equipe de saúde ou como uma categoria acima da própria equipe.

Cabe argumentar, nesse caso, que a ocorrência de uma reunião exclusiva para médicos não é um mal em si e poderia até facilitar a organização e funcionamento de uma reunião multiprofissional sob outra lógica e racionalidade. Assim como os demais profissionais, os médicos poderiam aprofundar a discussão dos casos de forma hermética e disciplinar, com enfoque no diagnóstico e terapêutica e utilizando os termos técnicos da área, o que costuma gerar descontentamento, exclusão, desentendimento, por parte dos outros profissionais nas reuniões em equipe. Ou seja, abre-se um caminho para que a reunião multiprofissional não gire em torno da questão médica, que já teria sido debatida na reunião própria, restando espaço na multiprofissional para que surgissem diferentes tipos de questões, bem como novas propostas e formas coletivas de lidar com problemas de saúde e de tomar decisões, que podem apontar para uma forma verdadeiramente multiprofissional de se trabalhar em equipe e de abordar o processo saúde-doença, criando-se uma lógica inovadora de discussão, organização e funcionamento desse coletivo de trabalho.

Apesar de a maioria dos profissionais, incluindo médicos, estar insatisfeita com o formato e dinâmica das reuniões multiprofissionais, todos os entrevistados reafirmaram que a existência de reuniões rotineiras com a participação dos diversos profissionais era de grande importância para o trabalho em equipe e a melhor integração das diferentes áreas na busca por uma atenção humanizada. Cabe reiterar que os espaços de reunião multiprofissional são importantes como facilitadores dos encontros e trocas interprofissionais. Entretanto, devemos enfatizar mais uma vez que a reunião dos diferentes profissionais em um mesmo espaço de discussão não garante necessariamente que haverá interação e relações de trabalho em equipe.

A reunião multiprofissional é uma das situações com forte potencial de trabalho em equipe, mas, apesar da fragmentação e para além dos espaços formais, os trabalhadores estabelecem na atividade seus encontros e trocas, 
tal qual referido por Schwartz, Duc e Durrive (2007a). Portanto, devemos valorizar o trabalho em equipe que pode se desenvolver nos momentos de reunião e a partir destes, mas com a precaução de considerar e também tornar visível a potência desses outros espaços não formais ou prescritos, ou seja, das ECRP que existem em qualquer atividade e só podem ser percebidas no concreto das práticas de atenção à saúde (Schwartz, Duc e Durrive, 2007a).

Louzada, Bonaldi e Barros (2007) afirmam que a dimensão coletiva do trabalho em equipe, em diversos momentos, não é imediatamente percebida, uma vez que um ato realizado de maneira isolada por um dos trabalhadores da equipe pode ser direcionado de forma indireta a membros ausentes na situação em questão. As necessidades do 'trabalho conjunto' fazem com que as ECRP existam de diferentes formas de acordo com os momentos específicos da situação de trabalho.

Essa potência do coletivo, expressa no trabalhar em equipe, será aumentada ou diminuída, ampliada ou constrangida dependendo da maneira como se dão as relações entre os trabalhadores, de como se opera a relação produção de saúde/produção de subjetividade (Barros e Barros, 2007, p. 83).

Verificou-se na pesquisa que existia vontade por parte de todos os profissionais de preencher esse vazio de normas que se apresentava diariamente em seus caminhos: o de encontrar uma forma de trabalhar junto para a produção de saúde, fortalecendo alianças, aumentando a capacidade de escuta e de reconhecimento do outro como aquele que possui e produz saber (Barros e Barros, 2007). Porém, além da racionalidade dominante, persistia uma postura de espera pela atitude alheia, demonstrando a necessidade de fomentar o protagonismo desses sujeitos, tornando visível a gestão que faziam do seu próprio trabalho e propiciando a busca de propostas de atuação em equipe baseadas numa outra racionalidade que não a médico-centrada, mas aquelas geradas com base nas experiências cotidianas, solidárias e singulares em cada setor ou serviço de saúde. Isto requer um processo de experimentação e aprendizagem para a formulação de propostas inovadoras de organização e funcionamento das reuniões multiprofissionais ou de outras iniciativas na construção de coletivos e redes.

Segundo Hennington (2008), na pesquisa e intervenção no campo da gestão em saúde, é necessário refletir sobre os valores que emergem no campo das microdecisões que ocorrem na atividade, a dinâmica dos processos de trabalho e a noção de experiência e subjetividade dos trabalhadores. Acrescenta, ainda, a autora que a humanização depende da inclusão do trabalhador da saúde nos processos de transformação pretendidos, e que estas transformações na gestão dos processos de trabalho envolvem o transitar em meio ao individual e o coletivo, o social, o econômico e o político; o con- 
fronto de interesses e a necessidade permanente de articulação e de negociação. Fazer a gestão dos processos de trabalho implica considerar gestão e atenção como indissociáveis, tal qual preconiza a PNH, e trabalho em saúde como trabalho vivo, produtor de sujeitos e orientado pela cogestão na produção do cuidado.

A gestão é conhecimento técnico, mas também inter(ação) de regimes do conhecer, em que o inter, o entre vem, paradoxalmente, primeiro indicando um plano do coletivo, um trabalhar-coletivo que antecede os trabalhadores. Se a gestão é função de gerir, melhor seria então dizer co-gerir, pois se trata de co-engendramento do processo de trabalhar (no nosso caso, produzir saúde) e de subjetivar (produção de trabalhadores) (Barros e Barros, 2007, p. 81, grifo das autoras).

Subjetivar no sentido de um reposicionamento visando à autonomia, não no plano da individualidade, mas da produção de sujeitos com postura ético-política na construção de um plano comum, coletivo, que os atravessa e constitui. Nas instituições de saúde, os trabalhadores são sujeitos dos processos de trabalho, podendo se aproximar ou se afastar de um novo projeto de atenção à saúde, e para que este possa emergir é preciso que eles se percebam e, assim, se tornem os agentes das mudanças (Pinheiro, Mattos e Barros, 2007; Scherer, Pires e Schwartz, 2009).

\section{Considerações finais}

A assistência fundamentada no modelo tradicional, biomédico, traz limitações ao trabalho em equipe, favorece a fragmentação da atenção, a produção de saúde centrada nos procedimentos e na doença, e não no usuário, e a concentração do poder de decisão na figura do médico, situando a atuação dos demais profissionais de forma periférica e com desigual valoração. Tal influência negativa que esse modelo exerce sobre as práticas e as relações interprofissionais merece destaque, pois ficou patente em várias falas bem como em diversos momentos e situações durante a pesquisa. Por outro lado, o desconforto presente evidencia o quanto é necessário que se construam outros projetos intelectuais forjados com base numa perspectiva éticopolítica que guiem as práticas em saúde na direção da integralidade e da humanização, por meio de ações integradas, resolutivas e que deem conta das dimensões biológicas, subjetivas e socioculturais no processo saúdedoença-cuidado.

Construir formas de trabalhar em equipe orientadas por uma racionalidade diversa da hegemônica na assistência e que caminhem na direção da humanização enseja ainda que o modelo de gestão seja repensado com o 
objetivo de fomentar espaços de gestão colegiada no dia a dia dos serviços, aumentando a comunicação e o grau de transversalização entre sujeitos, em que cada um possa ser e se sinta protagonista, respeitado e valorizado em relação ao seu saber e fazer e, ao mesmo tempo, se responsabilize pelos rumos da atenção prestada. Um modo de fazer gestão em que possam ser discutidos os problemas, construídos consensos e pactuadas decisões de forma coletiva e democrática, para que as relações interprofissionais sejam também mais democráticas e voltadas para o bem comum.

A possibilidade de mudança das práticas de saúde encontra potencial nos próprios trabalhadores e em suas escolhas na atividade diante das demandas e necessidades dos usuários. Essas transformações não são isentas de esforço e conflitos, exigem sair da 'zona de conforto', e envolvem escolhas quanto ao tipo de relações interprofissionais que se deseja construir e à postura ético-política que se pretende adotar nas práticas.

Acreditamos que as mudanças só podem acontecer a partir dos próprios sujeitos-trabalhadores, de um reposicionamento desencadeado pelo desconforto coletivo e propiciado por um movimento de 'contágio'. Desvelar a atividade desses profissionais em alguma dimensão na situação de trabalho pode contribuir para fomentar seu protagonismo como agentes de transformação dos processos de trabalho e das práticas de atenção à saúde, bem como resultar em reflexões, negociações e escolhas que caminhem na direção da construção de um trabalho em equipe pautado em relações solidárias, democráticas e de corresponsabilidade entre os diferentes sujeitos envolvidos na produção de saúde.

\section{Nota do Editor}

Este texto apresenta parte dos resultados da dissertação de mestrado Trabalho em equipe multiprofissional: relações interprofissionais e humanização da assistência hospitalar em doenças infecciosas, do Programa de Pós-Graduação em Saúde Pública da Escola Nacional de Saúde Pública Sergio Arouca (Ensp/Fiocruz), defendida por Cíntia Garcia Cardoso, em 29 de novembro de 2010, sob orientação de Élida Azevedo Hennington. O trabalho integra a pesquisa "Gestão do trabalho e produção de saúde: práticas de humanização no Ipec", de Élida Azevedo Hennington, financiada pela Fundação Carlos Chagas Filho de Amparo à Pesquisa do Estado do Rio de Janeiro (Faperj), Conselho Nacional de Desenvolvimento Científico e Tecnológico (CNPq) e Fiocruz/RJ. 


\title{
Notas
}

\begin{abstract}
1 Cirurgiã-dentista da Secretaria Municipal de Saúde de Itaguaí, Itaguaí, Rio de Janeiro, Brasil. Mestre em Saúde Pública pela Escola Nacional de Saúde Pública Sergio Arouca, da Fundação Oswaldo Cruz (Ensp/Fiocruz). <cintiagarcia004@hotmail.com> Correspondência: Estrada do Tindiba, 1.493, bloco 3, apto. 304, Pechincha, CEP 22740-361, Rio de Janeiro, Brasil.

2 Professora e pesquisadora do Programa de Pós-Graduação em Saúde Pública da Escola Nacional de Saúde Pública Sergio Arouca, da Fundação Oswaldo Cruz (Ensp/Fiocruz), e do Programa de Pós-Graduação em Pesquisa Clínica em Doenças Infecciosas do Instituto de Pesquisa Clínica Evandro Chagas (Ipec) da Fiocruz. Doutora em Saúde Coletiva pela Universidade Estadual de Campinas (Unicamp). <elida.hennington@ipec.fiocruz.br>
\end{abstract}

\section{Referências}

ABUHAB, Deborah et al. O trabalho em equipe multiprofissional no CAPS III: um desafio. Revista Gaúcha de Enfermagem, Porto Alegre, v. 26, n. 3, p. 369-80, 2005.

ARAÚJO, Marize Barros de Souza; ROCHA, Paulo de Medeiros. Trabalho em equipe: um desafio para a consolidação da estratégia de saúde da família. Ciência \& Saúde Coletiva, Rio de Janeiro, v. 12, n. 2, p. 455-464, 2007.

BARROS, José Augusto Cabral de. Pensando o processo saúde doença: a que responde o modelo biomédico? Saúde e Sociedade, São Paulo, v. 11, n. 1, p. 67-84, 2002.

BARROS, Maria Elizabeth Barros de; BARROS, Regina Benevides de. A potência formativa do trabalho em equipe no campo da saúde. In: PINHEIRO, Roseni; MATTOS, Ruben Araujo de; BARROS, Maria Elizabeth Barros de (Orgs.). Trabalho em equipe sob o eixo da integralidade: valores, saberes e práticas. Rio de Janeiro: IMS/Uerj, Cepesc, Abrasco, 2007. p. 75-84.

BRASIL. Ministério da Saúde. SecretariaExecutiva. Núcleo Técnico da Política Nacional de Humanização. HumanizaSUS: Política
Nacional de Humanização - a humanização como eixo norteador das práticas de atenção e gestão em todas as instâncias do SUS. Brasília: Ministério da Saúde, 2004.

Ministério da Saúde. Secretaria de Atenção à Saúde. Núcleo Técnico da Política Nacional de Humanização. HumanizaSUS: documento base para gestores e trabalhadores do SUS. 4. ed. Brasília: Ministério da Saúde, 2008.

Ministério da Saúde. Secretaria de Atenção à Saúde. Política Nacional de Humanização da Atenção e Gestão do SUS. Clínica ampliada e compartilhada. 1. ed. Brasília: Ministério da Saúde, 2009a.

Ministério da Saúde. Secretaria de Atenção à Saúde. Política Nacional de Humanização da Atenção e Gestão do SUS. Gestão participativa e cogestão. 1. ed. Brasília: Ministério da Saúde, 2009b.

CANOLETTI, Bianca. Trabalho em equipe de saúde e de enfermagem: análise sistemática da literatura. Dissertação de Mestrado, São Paulo: Escola de Enfermagem, Universidade de São Paulo, 2008. 
CAPRARA, Andrea; FRANCO, Anamélia Lins e Silva. A relação paciente-médico: para uma humanização da prática médica. Cadernos de Saúde Pública, Rio de Janeiro, v. 15, n. 3, p. 647-654, 1999.

CECÍLIO, Luiz Carlos de Oliveira; MERHY, Emerson Elias. A integralidade do cuidado como eixo da gestão hospitalar. In: PINHEIRO, Roseni; MATTOS, Ruben Araujo (Orgs.). Construção da integralidade: cotidiano, saberes e práticas em saúde. Rio de Janeiro: IMS/Uerj, Abrasco, 2003. p. 197-210.

COLOMÉ, Isabel Cristina dos Santos; LIMA, Maria Alice Dias da Silva; DAVIS, Roberta. Visão de enfermeiras sobre as articulações das ações de saúde entre profissionais de equipes de saúde da família. Revista da Escola de Enfermagem da USP, São Paulo, v. 42, n. 2, p. 256-261, 2008.

COSTA, Roberta Kaliny de Souza; ENDERS, Bertha Cruz; MENEZES, Rejane Maria Paiva de. Trabalho em equipe de saúde: uma análise contextual. Ciência \& Saúde Coletiva, Rio de Janeiro, v. 7, n. 4, p. 530-536, 2008.

FORTUNA, et al. O trabalho de equipe no Programa de Saúde da Família: reflexões a partir de conceitos do processo grupal e de grupos operativos. Revista Latino-Americana de Enfermagem, Ribeirão Preto, v. 13, n. 2, p. 262-268, 2005.

GOMES, Elisiane dos Santos; ANSELMO, Maria Elenir de Oliveira; LUNARDI FILHO, Wilson Danilo. As reuniões de equipe como elemento fundamental na organização do trabalho. Revista Brasileira de Enfermagem, Brasília, v. 53, n. 3, p. 472-480, 2000.

GOMES, Rafael da Silveira Gomes; PINHEIRO, Roseni; GUIZARDI, Francini Lube. Orquestração do trabalho em saúde: um debate sobre a fragmentação das equipes. In: PINHEIRO, Roseni; MATTOS, Ruben Araujo (Orgs.). Construção social da demanda: direito à saúde, trabalho em equipe, participação e espaços públicos. Rio de Janeiro: Cepesc/Uerj, Abrasco, 2005. p. 105-116.
GRANDO, Maristel Kasper; DALL'AGNOL, Clarice Maria. Desafios do processo grupal em reuniões de equipe da Estratégia Saúde da Família. Escola Anna Nery Revista de Enfermagem, Rio de Janeiro, v. 14, n. 3, p. 504-510, 2010.

HENNINGTON, Élida Azevedo. Gestão dos processos de trabalho e humanização em saúde: reflexões a partir da ergologia. Revista de Saúde Pública, São Paulo, v. 42, n. 3, p. 555-61, 2008.

HONORATO, Carlos Eduardo de Moraes; PINHEIRO, Roseni. "Trabalho político": construindo uma categoria analítica para análise da integralidade como dispositivo do trabalho em equipe na saúde. In: PINHEIRO, Roseni; MATTOS, Ruben Araujo de; BARROS, Maria Elizabeth Barros de. (Orgs.). Trabalho em equipe sob o eixo da integralidade: valores, saberes e práticas. Rio de Janeiro: IMS/Uerj, Cepesc, Abrasco, 2007. p. 85-110.

JACOB FILHO, Wilson; SITTA, Maria do Carmo. Interprofissionalidade. In: NETTO, Matheus Papaléo. Gerontologia: a velhice e o envelhecimento em visão globalizada. São Paulo: Atheneu, 2002. p. 440-450.

KOIFMAN, Lilian. O modelo biomédico e a reformulação do currículo médico da Universidade Federal Fluminense. História, Ciências, Saúde - Manguinhos, Rio de Janeiro, v. 8, n. 1, p. 48-70, 2001.

LIMA, Maria Alice Dias da Silva; ALMEIDA, Maria Cecília Puntel de. O trabalho de enfermagem na produção de cuidados de saúde no modelo clínico. Revista Gaúcha de Enfermagem, Porto Alegre, v. 20, n. esp., p. 86-101, 1999.

LOUZADA, Ana Paula Figueiredo; BONALDI, Cristiana; BARROS, Maria Elizabeth Barros de. Integralidade e trabalho em equipe no campo da saúde: entre normas antecedentes e recentradas. In: PINHEIRO, Roseni; MATTOS, Ruben Araujo de; BARROS, Maria Elizabeth Barros de (Orgs.). Trabalho em equipe 
sob o eixo da integralidade: valores, saberes e práticas. Rio de Janeiro: IMS/Uerj, Cepesc, Abrasco, 2007. p. 37-52.

MATTOS, Ruben Araujo de. A integralidade na prática (ou sobre a prática da integralidade). Cadernos de Saúde Pública, Rio de Janeiro, v. 20, n. 5, p. 1.411-1.416, 2004.

MINAYO, Maria Cecília de Souza. O desafio do conhecimento: pesquisa qualitativa em saúde. 11. ed. São Paulo: Hucitec, 2008.

PASCHE, Dário Frederico; PASSOS, Eduardo; HENNINGTON, Élida Azevedo. Cinco anos da Política Nacional de Humanização: trajetória de uma política pública. Disponível em $<$ www.cienciaesaudecoletiva.com.br/artigos/ artigo_int.php?id_artigo=5996>. Acesso em: 10 abr. 2010.

PEDROSO, Raquel Turci; VIEIRA, Maria Edna Moura. Humanização das práticas de saúde: transversalizar em defesa da vida. Interface - Comunicação, Saúde e Educação, Botucatu, v. 13, supl. 1, p.695-700, 2009.

PEDUZZI, Marina. Equipe multiprofissional de saúde: a interface entre trabalho e interação. Tese de Doutorado, Campinas: Faculdade de Ciências Médicas, Universidade de Campinas, 1998.

Equipe multiprofissional de saúde: conceito e tipologia. Revista de Saúde Pública, São Paulo, v. 35, n. 1, p. 103-9, 2001.

Trabalho em equipe de saúde no horizonte normativo da integralidade, do cuidado e da democratização das relações de trabalho. In: PINHEIRO, Roseni; MATTOS, Ruben Araujo de; BARROS, Maria Elizabeth Barros de (Orgs.). Trabalho em equipe sob o eixo da integralidade: valores, saberes e práticas. Rio de Janeiro: IMS/Uerj, Cepesc, Abrasco, 2007. p. 161-177.

PINHEIRO, Roseni; MATTOS, Ruben Araujo de; BARROS, Maria Elizabeth Barros de (Orgs.). Trabalho em equipe sob o eixo da integralidade: valores, saberes e práticas. Rio de Janeiro: IMS/Uerj, Cepesc, Abrasco, 2007.
PINHO, Márcia Cristina Gomes de. Trabalho em equipe de saúde: limites e possibilidades de atuação eficaz. Ciências \& Cognição, Rio de Janeiro, v. 8, p. 68-87, 2006.

SCHERER, Magda Duarte dos Anjos; PIRES, Denise; SCHWARTZ, Yves. Trabalho coletivo: um desafio para a gestão em saúde. Revista de Saúde Pública, São Paulo, v. 43, n. 4, p. 721-25, 2009.

SCHRAIBER, Lilia Blima et al. Planejamento, gestão e avaliação em saúde: identificando problemas. Ciência \& Saúde Coletiva, Rio de Janeiro, v. 4, n. 2, p. 221-242, 1999.

SCHWARTZ, Yves. A comunidade científica ampliada e o regime de produção de saberes. Trabalho \& Educação, Belo Horizonte, n. 7, p. 38-46, 2000.

. Trabalho e saber. Trabalho \& Educação, Belo Horizonte, v. 12, n. 1, p. 1-14, 2003.

Entrevista. Trabalho, Educação e Saúde, Rio de Janeiro, v. 4, n. 2, p. 457-466, 2006.

SCHWARTZ, Yves; DUC, Marcelle; DURRIVE, Louis. A linguagem em trabalho. In: SCHWARTZ, Yves; DURRIVE, Louis (Orgs.). Trabalho e ergologia: conversas sobre a atividade humana. Niterói: EdUFF, 2007a. p. 133-166. cap. 5.

Trabalho e uso de si. In: SCHWARTZ, Yves; DURRIVE, Louis (Orgs.). Trabalho e ergologia: conversas sobre a atividade humana. Niterói: EdUFF, 2007b. p. 191-206. cap. 7.

O homem, o mercado e a cidade. In: SCHWARTZ, Yves; DURRIVE, Louis (Orgs.). Trabalho e ergologia: conversas sobre a atividade humana. Niterói: EdUFF, 2007c. p. 249-275. cap. 9.

SILVA, Iêda Zilmara de Queiroz Jorge da; TRAD, Leny Alves Bomfim. O trabalho em equipe no PSF: investigando a articulação técnica e a interação entre os profissionais. 
Interface - Comunicação, Saúde e Educação, Botucatu, v. 9 , n. 16, p. 25-38, set. 2004/fev. 2005.

SOUZA, Luiz Augusto de Paula; MENDES, Vera Lúcia Ferreira. O conceito de humanização na Política Nacional de Humanização (PNH). Interface - Comunicação, Saúde e Educação, Botucatu, v. 13, supl. 1, p. 681-688, 2009.

Recebido em 02/06/2011

Aprovado em 09/06/2011 